\author{
Klasifikasi Disabilitas Atlet Anggar Kursi Roda (Wheelchair Fencing) Untuk Kejuaraan \\ Internasional
}

Joko Nugroho

\title{
KLASIFIKASI DISABILITAS ATLET ANGGAR KURSI RODA (WHEELCHAIR FENCING) UNTUK KEJUARAAN INTERNASIONAL
}

\author{
Joko Nugroho
}

PENJASKES FKOR UNS SURAKARTA

\begin{abstract}
Abstrak
Olahraga disabilitas di Indonesia sudah sangat diperhatikan pemerintah Republik Indonesia dengan ditandai adanya kebijakan yang sudah disamakan dengan cabang olahraga yang normal. Pemahaman akan olahraga disabilitas di masyarakat khususnya bagi para penyandang disabiltas di Indonesia masih sangat kurang khususnya cabang olahraga anggar kursi roda, keadaan tersebut dikarenakan belum adanya sosialisasi dan pemahaman akan nomor-nomor yang dipertandingkan dan kategori klasifikasi atlet yang berhak mengikuti akan olahraga khusus anggar kursi roda. Nomornomor pertandingan dan klasifikasi atlet di olahraga anggar kursi roda adalah foil individual katagori klasifikasi A,B,C dan tim, Epee individual katagori klasifikasi A, B, C dan Tim dan Sabre individual katagori A, B, C dan Tim. Penentuan katagori klasifikasi atlet anggar kursi roda dilakukan dengan tes medik oleh dokter spesialis ortopedi dan tes funsional anggota gerak tubuh. Tes fungsioanal terdiri dari empat item tes yaitu tes satu sampai dengan tes ke empat, dari tes fungsional tersebut sudah ditentukan poin-poin untuk menghitung tingkat kemampuan anggota gerak tubuh atlet, penghitungan poin tes dan pengamatan visual atlet saat melakukan gerakan saat pemanasan sebelum pertandingan akan di kalkulasi untuk menentukan kelas klasifikasi atlet anggar kursi roda. Katagori klsifikasi atlet anggar kursi roda adalah: A untuk atlet yang masuk di kelas 3 dan 4, B untuk atlet yang masuk di kelas 2 dan $\mathrm{C}$ untuk atlet yang masuk di kelas 1A-1B. Dengan adanya pemahaman masyarakat khususnya penyandang disabilitas yang memiliki potensi menekuni cabang olahraga anggar kursi roda ini maka diharapkan peningkatan prestasi anggar kursi roda di Indonesia semakin baik dan secara otomatis bagi penyandang disabilitas yang memiliki prestasi di multi event internasional akan meningkatkan taraf ekonomi dan kehidupannya.
\end{abstract}

Kata kunci : Disabilitas, anggar kursi roda, katagori klasifikasi atlet.

\section{PENDAHULUAN}

Pemerintah Republik Indonsia telah mencanangkan bahwa olahraga penyandang disabilitas sejajar dengan olahraga normal lainnya, baik dari fasilitas penunjang latihan seperti sarana dan prasarana, rekrutmen atlet, pengadaan pemusatan latihan, honor dan gaji atlet dan pelatih sampai dengan bonus yang nanti diperoleh dalam pencapaian pretasi di multi 


\section{Klasifikasi Disabilitas Atlet Anggar Kursi Roda (Wheelchair Fencing) Untuk Kejuaraan Internasional}

Joko Nugroho

event. Pemerintah Republik Indonesia juga berusaha untuk menyediakan dan membangun fasilitas khusus bagi penyandang disabilitas di setiap provinsi untuk tempat pemusat latihan atlet serta akan memberikan perhatian secara khusus untuk pengembangan olahraga disabilitas.

Dalam perkembangan olahraga disabilitas di Indonesia saat ini masih banyak menemui kendala, kendala tersebut banyak di sebabkan oleh sarana dan prasarana dan kurang mengertinya masyarakat akan cabang-cabang olahraga khusus bagi penyandang disabilitas karena minimnya informasi dan masih kurangnya sosialisasi bagi masyarakat yang mememerlukannya. Cara pandang masyarakat secara umum yang berkaitan dengan olahraga disabilitas masih sangat tradisional, seringkali beranggapan bahwa olahraga disabilitas hanya sekedar untuk persyaratan suatau event yang diselenggarakan oleh pemerintah, padahal saat ini cabang olahraga disabilitas sudah sangat maju dalam menerapkan ilmu pengetahuan dan tehnologi dan hampir sama dengan penangannan olahraga bagi atlet yang normal. Perkembangan cabang olahraga disabilitas khususnya anggar kursi roda atau istilah internasionalnya wheelchair fencing di Indonesia terkhusus dalam dua tahun terahkir ini mengalami kemajuan yang pesat, terlebih dalam multi event Asian Para Games ke-4 di Jakarta Indonesia tahun 2018 kemarin dipertandingkan. Antusias masyarakat setelah menyaksikan anggar kursi roda di Asian Para Games sangat tinggi dan semangat melaksanakan olahraga anggar kursi roda bagi penyandang disabilitas tersebut sangat tinggi sampai di bawa ke daerah-daerah dan dikembangkan melalui tempat-tempat latihan umum bagi atlet yang normal dengan cara digabungkan menjadi satu dalam pelaksanaan latihannya.

Anggar kursi roda adalah salah satu cabang olah raga bagi penyandang disabilitas di Indonesia yang menggunakan senjata dan pada saat ini sedang berkembang menjadi olahraga ketangkasan dengan senjata yang menekankan pada teknik kemampuan seperti memotong, menusuk atau menangkis senjata lawan dengan menggunakan keterampilan dalam memanfaatkan kelentukan togok dan kelincahan tangan. Anggar kursi roda secara permainan dan perlengkapan sama dengan permainan anggar yang dimainkan oleh atlet umum. Untuk perlengkapan yang melekat pada atlet seperti pakaian,seragam, kaos tangan, kaos kaki, masker, jaket elektrik,sepatu,plastron sampai dengan senjata semua sama dengan atlet normal, yang membedakan hanya terletak di penggunaan prasarana pertandingan. Di anggar 


\section{Klasifikasi Disabilitas Atlet Anggar Kursi Roda (Wheelchair Fencing) Untuk Kejuaraan Internasional}

Joko Nugroho

kursi roda dalam bertanding menggunakan kursi roda dan frame(alat pengikat kursi roda dengan piste/landasan) sebagai sarana utama, kursi roda tidak di gunakan secara aktif untuk maju mundur sebagai sarana pengganti kaki seperti di anggar yang normal melainkan dipergunakan frame untuk mengikat kursi roda agar tidak bisa bergerak, disini hanya kelentukan, kelincahan togok dan waktu reaksi serta koordinasi mata tangan yang menentukan tingkat keberhasilan seorang atlet anggar kursi roda.

Dalam pelaksanaan sebuah pertandingan anggar kursi roda di bagi menjadi beberapa nomor pertandingan dan kelas/klasifikasi menurut disabilitas atletnya. Klasifikasi atlet sesuai dengan disabilitasnya tersebut masih sangat minim bahkan belum banyak dimengerti oleh masyarakat saat ini. Dengan keadaan tersebut maka perlu adanya pengertian dan pengetahuan tentang nomor-nomor cabang olahraga anggar kursi roda dan bagaimana klasifikasi atlet sesuai dengan disabiltasnya di cabang olahraga anggar kursi roda. Dengan adanya pengetahuan nomor dan klasifikasi atlet anggar kursi roda maka diharapkan perkembangan dan peningkatan prestasi cabang olahraga anggar kursi roda di Indonesia semakin maju dan berkembang ke arah yang lebih baik.

\section{PEMBAHASAN}

\section{A. NOMOR-NOMOR PERTANDINGAN ANGGAR KURSI RODA UNTUK PERTANDINGAN INTERNASIONAL}

Nomor pertandingan anggar kursi roda yang dilaksanakan dalam event-event internasional oleh induk organisasi dunia/federasi kursi roda IWAS(Int'I Wheelchair \& Amputee Sport) dan khusus anggar kursi roda IWF (Int'I Wheelchair Fencing) adalah sebagai berikut :

\begin{tabular}{|l|l|}
\hline \multicolumn{2}{|c|}{ Event } \\
\hline \multirow{2}{*}{ Foil } & Individual Katagori A \\
\cline { 2 - 2 } & Individual Katagori B \\
\cline { 2 - 2 } & Individual Katagori C \\
\hline & Team \\
\hline & Individual Katagori A \\
\hline & Individual Katagori B \\
\hline
\end{tabular}




\section{Klasifikasi Disabilitas Atlet Anggar Kursi Roda (Wheelchair Fencing) Untuk Kejuaraan Internasional}

Joko Nugroho

\begin{tabular}{|l|l|} 
& Individual Katagori C \\
\cline { 2 - 2 } Epee & Team \\
\hline \multirow{3}{*}{ Sabre } & Individual Katagori A \\
\cline { 2 - 2 } & Individual Katagori B \\
\cline { 2 - 2 } & Individual Katagori C \\
\cline { 2 - 2 } & Team \\
\hline
\end{tabular}

Atlet bertanding dengan kursi roda yang dipasang pada frame yang diikat ke landasantau piste. Dengan demikian memberi atlet kebebasan bergerak di tubuh bagian atas mereka, sambil menjaga atlet tetap aman di kursi rodanya. Anggar kursi roda ini dilakukan pada landasan (piste) berukuran 4 meter x 1,5 m.

Berdasarkan nomor senjata di bagi menjadi tiga nomor individu dan 1 nomor tim yaitu :

a. Foil.

Foil atau dalam bahasa Indonesia senjata Floret adalah nomor pertandingan yang khusus menggunakan senjata floret, jenis senjata, pegangan dan sasaran yang masuk dalam nomor senjata floret ini adalah sebagai berikut;

Senjata foil/floret

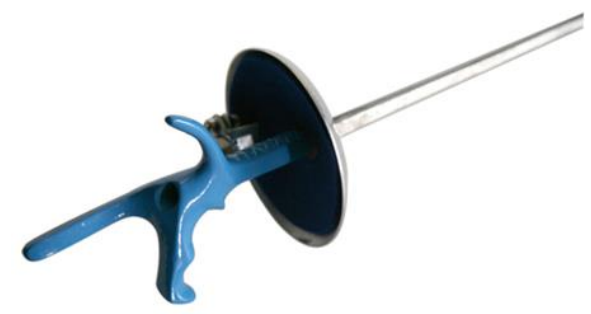

Foil adalah senjata yang jenis penggunaannya hanya di dorong atau disodorkan ke depan saja tanpa diikuti gerakan menyabet dari arah samping kiri atau kanan badan. Gerakan serangan hanya sebatas gerakan lengan ke depan, atau putaran pergelangan tangan untuk mengecoh lawan dengan arah sasaran yang sudah ditentukan yaitu ke bagian togok/batang tubuh bagian depan dan belakang saja. Target pada foil tidak termasuk tungkai dan kepala, batas atas ada di bawah clavikula, scapula dan batas bawah diatas tulang gelang panggul/pelvic girdle depan dan belakang. Untuk jarak antar pemain dengan cara mengukur rentang lengan seperti saat menyerang dengan senjata dalam posisi duduk tegak lurus sesuai 


\section{Klasifikasi Disabilitas Atlet Anggar Kursi Roda (Wheelchair Fencing) Untuk Kejuaraan Internasional}

\section{Joko Nugroho}

tanda garis tengah di pakaian anggar yang berada di tengah persis sandaran kursi roda atlet dengan posisi lawan juga duduk tegak lurus diatas kursi roda dengan tanda yang sudah ditentukan di pakaian atlet di tengah -tengah badan dan tanda garis disesuaikan dengan tanda yang berada tepat di tengah-tengah sandaran kursi roda, kemudian satu pemain anggar akan menekuk lengan bawah secara vertikal dan lengan atas secara horisontal membentuk sudut 90 derajat, ujung senjata harus menempel di siku bagian dalam pemain satunya, khusus untuk katagori $\mathrm{C}$ dengan gerakan yang sangat terbatas titik diambil $10 \mathrm{CM}$ di dalam tepi luar siku.

\section{Foil}

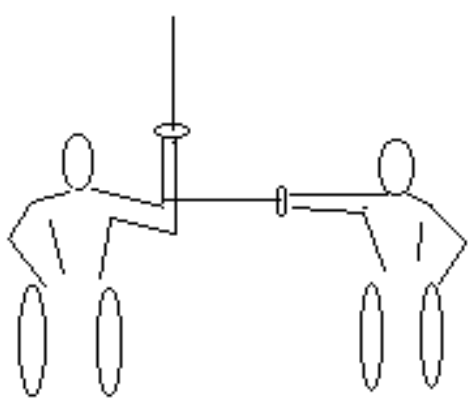

Gambar; jarak antar atlet Foil

b. EPEE

Epee atau dalam bahasa Indonesia di sebut senjata Degen adalah nomor pertandingan yang khusus menggunakan senjata Degen, jenis senjata, pegangan dan sasaran yang masuk dalam nomor senjata Degen ini adalah sebagai berikut;

Senjata Epee/Degen

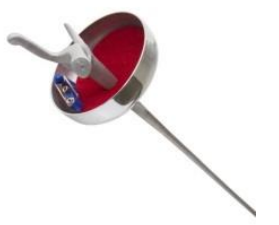

Senjata epee atau degen dalam permainan anggar kursi roda bersifat menusuk ke depan dan memainkan pergelangan tangan serta lengan bawah untuk memasukkan tusukan ke sasaran yang sudah ditentukan. Sasaran atau target tusukan senjata Epee ini meliputi seluruh 


\section{Klasifikasi Disabilitas Atlet Anggar Kursi Roda (Wheelchair Fencing) Untuk Kejuaraan Internasional}

Joko Nugroho

bagian atas tubuh termasuk leher dan kepala baik sisi depan maupun belakang badan kecuali lengan dan tangan. Untuk bagian tubuh di bawah garis horizontal tubuh yang ditarik dari antara bagian lipatan paha dan batang tubuh tidak termasuk sasaran yang sah. Pada bagian ini ditutup dengan kain elektrik atau disebut Apron yang berguna untuk memutuskan aliran listrik yang menghubungkan dengan recording/papan nilai, jadi apabila tusukan mengenai apron maka secara otomatis tanda sahnya serangan tidak muncul di recording. Apron ini dikaitkan oleh kabel ke ground agar supaya kalau ada kontak langsung bisa terputus aliran listriknya ke tanda sah dan tidaknya serangan.

Jarak antar pemain dalam pertandingan epee ini seperti yang dilaksanakan di nomor foil , posisi duduk dan pengukuan lengan dengan senjata sama dengan foil yang membedakan hanya ada di letak senjata dengan siku, kalau di foil senjata berada di sisi dalam siku sedangkan untuk epee berada di sisi terluar dari siku. Untuk katagori $\mathrm{C}$ dengan gerakan yang sangat terbatas harus menentukan ukuran mencapai titik $10 \mathrm{~cm}$ di dalam tepi luar siku.

\section{c. SABRE}

Sabre atau dalam bahasa Indonesia di sebut senjata Sabel adalah nomor pertandingan yang khusus menggunakan senjata Sabel, jenis senjata, pegangan dan sasaran yang masuk dalam nomor senjata Sabel ini adalah sebagai berikut;

Senjata Sabel/sabre

Senjata sabel dalam penggunaannya dapat digunakan untuk menusuk, memotong dan memukul serta melecutkan senjata dengan pergelangan tangan atau seluruh lengan, segala jenis serangan apabila mengenai sasaran yang sudah ditentukan dianggap sah dan dihitung sebagai point dalam sebuah pertandingan. Sasaran permainan Sabel ini meliputi seluruh 


\section{Klasifikasi Disabilitas Atlet Anggar Kursi Roda (Wheelchair Fencing) Untuk Kejuaraan Internasional}

Joko Nugroho

bagian tubuh di atas garis horizontal yang di tarik diantara bagian atas lipatan paha dan togok pada saat dalam posisi duduk di atas kursi roda. Untuk menentukan jarak antar atlet yang tepat, atlet duduk tegak di tengah kursi roda. Salah satu pemain menekuk lengan bawah vertikal dan lengan atas horisontal dan siku menunjuk ke atlet anggar lainnya. Atlet anggar lainnya dengan memeganng senjata menjulurkan lengannya secara lurus sampai menyentuh sisi luar siku lawan sebagai titik perkenaan senjata dan siku dan atlet lainnya melakukan sebaliknya. Dalam kasus pemain dengan memiliki panjang lengan yang berbeda salah satu yang memiliki lengan yang lebih pendek dapat memilih jarak yang berada diantara jarak dengan lawannya tersebut. Atlet dengan katogori $\mathrm{C}$ yang memiliki gerakan yang sangat terbatas harus menentukan titik $10 \mathrm{~cm}$ ke dalam tepi luar siku.

\section{Epee and Sabre}

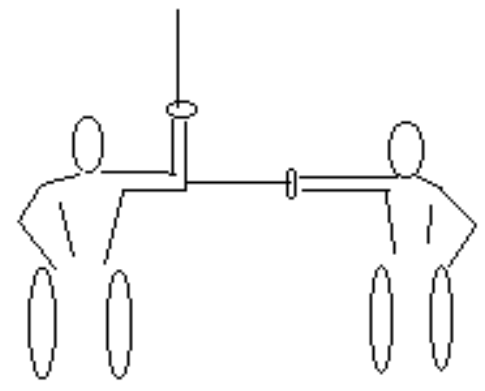

Gambar: jarak antar atlet Degen dan Sabel

d. Tim

Pertandingan team di anggar kursi roda baik nomor foil, epee dan sabre terdiri dari 4 atlet yang satu sebagai atlet cadangan, di setiap team terdapat peraturan yang menyertainya, apabila pertandingan team diikuti klasifikasi A dan B saja tanpa klasifikasi C maka dalam setiap team harus ada minimal satu atlet yang berklasifikasi B. Berdasarkan pengalaman di event-event kejuaraan internasional seperti kejuaraan dunia dan multi event seperti Asian Para games, Paralimpik Games katagori C sering ditiadakan di dalam event tersebut dikarenakan sedikitnya atlet yang mengikutinya. 


\section{Klasifikasi Disabilitas Atlet Anggar Kursi Roda (Wheelchair Fencing) Untuk Kejuaraan Internasional}

Joko Nugroho

\section{B. PENENTUAN KLASIFIKASI ATLET ANGGAR KURSI RODA DALAM PERTANDINGAN INTERNASIONAL.}

\section{a. TES FUNGSIONAL ATLET ANGGAR KURSI RODA}

Disetiap pertandingan anggar kursi roda yang dilaksanakan oleh IWAS setiap atlet harus bisa menunjukkan kartu klasifikasi yang resmi dikeluarkan IWAS, kartu klasifikasi tersebut didapatkan dengan pemeriksaan medis dan fungsional melalui rangkaian tes yang sudah baku dan selalu dipakai di setiap pertandingan resmi. Aturan resmi untuk klasifikasi anggar kursi roda pertama kali disusun oleh Leslie Veal, ketua Sub-komite Anggar Internasional Stoke Mandeville Games, pada awal 1970-an. Revisi besar terakhir dari aturanaturan ini adalah pada tahun 1988 oleh Theo Van Leeuwen, Ketua Komite 1984-1992, Brian Dickinson, dan Vittorio Loi.

Setiap atlet anggar kursi roda harus memiliki semua syarat yang dikeluarkan oleh komite klasifikasi dengan diikuti hasil pemeriksaan kreteria disabilitas minimal agar dapat bertanding. Komite klasifikasi akan mengeluarkan kartu klasifikasi dengan status

1. Klasifikasi baru

2. Klasifikasi Review

3. Klasifikasi Konfirmasi

Klasifikasi baru diperuntukan bagi atlet yang baru pertama kali mengikuti tes klasifikasi yang hasilnya harus di klarifikasi ulang pada saat pertandingan sesudahnya. Disini atlet anggar kursi roda saat nanti akan mengikuti kejuaraan berikutnya sesuai dengan kalender IWAS diharuskan menjalani rangkaian tes yang sama dan akan mendapatkan kartu klasifikasi lagi. Kemungkinan besar hasil yang diperoleh sama dengan hasil tes yang pertama.

Klasifikasi Review diperuntukan oleh atlet yang dalam pelaksanaan tes klasifikasi pertama masih meragukan, hasil yang diperoleh masih bersifat sementara dan harus di lakukan tes ulang saat pertandingan berikutnya, ada kemungkinan hasil tes klasifikasi akan berbeda dengan hasil tes yang pertama, ada kemungkinan dari klasifikasi A bisa menjadi klasifikasi B. Untuk kartu klasifikasi review ini sering diperuntukan bagi atlet yang menyatakan protes kepada komite klasifikasi atas hasil yang diperoleh yang tidak sesuai dengan keinginan diri atlet tersebut. 


\section{Klasifikasi Disabilitas Atlet Anggar Kursi Roda (Wheelchair Fencing) Untuk Kejuaraan Internasional}

Joko Nugroho

Klasifikasi konfirmasi diperuntukan bagi atlet anggar kursi roda yang sudah final hasil tes klasifikasinya . Atlet tidak perlu melakukan tes ulang klasifikasi karena komite klasifikasi sudah sangat yakin akan kemampuan atlet sesuai dengan disibalitasnya.

Kartu klasifikasi atlet ini harus di simpan dan didokumenkan secara baik agar setiap mengikuti pertandingan bisa melampirkan sebagai syarat pendaftaran atlet dalam nomor pertandingan yang akan diikutinya, kartu klasifikasi ini akan diperbaiki dalam jangka waktu satu tahun sekali, setelah satu tahun setiap atlet anggar kursi roda harus mengulangi rangkaian tes klasifikasi untuk mendapatkan status klasifikasi yang baru.

Tes fungsional akan dilakukan di kursi roda yang terdiri dari evaluasi ekstensi dan kemampuan lateral kecenderungan dada di posisi yang berbeda, dengan atau tanpa menggunakan senjata. Gerakan yang diuji mengulangi gerakan teknis tertentu. Seperti gerakan mamajukan badan untuk menyerang, di mana gerakannya adalah kecenderungan lateral mendadak disertai improvisasi badan dengan senjata di tangan dan perpanjangan siku secara simultan, atau mengulangi gerakan serangan sebanyak mungkin dengan diikuti gerakan pengembalian cepat untuk membawa badan ke posisi siap semula disertai menghindari serangan lawan, dalam kecenderungan ke sisi yang berlawanan, untuk menentukan "titik pengukuran." Setiap gerakan dikaitkan dengan skor poin yang ditentukan oleh fungsi selama tes:

0 Poin : tidak ada fungsi, gerakan tidak dapat diberlakukan

1 Poin : eksekusi sangat lemah, gerakan minimum

2 Poin : eksekusi lemah, gerakan adil

3 Poin : eksekusi normal

Tes-tes fungsional yang dilakukan untuk menentukan kelas klasifikasi adalah sebagai berikut;

1) Tes I

Tes ekstensi otot punggung: Subjek, duduk di kursi roda dengan posisi tegak, dari posisi tegak badan di bungkukkan ke depan kemudian mencoba untuk kembali ke posisi tegak, mengerutkan otot-otot punggung dan menjaga anggota tubuh bagian atas retroflexed. Selama pelaksanaan tes ke satu ini badan bebas dan lengan tangan tidak boleh berpegangan pada kursi roda. 


\section{Klasifikasi Disabilitas Atlet Anggar Kursi Roda (Wheelchair Fencing) Untuk Kejuaraan Internasional}

Joko Nugroho

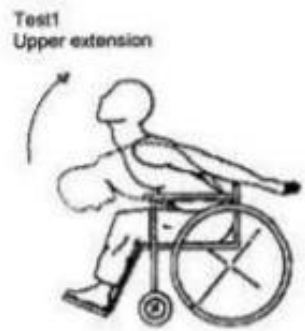

Gambar tes I

2) Tes II

Tes keseimbangan lateral dengan anggota tubuh bagian atas yang sudah ditentukan. Atlet harus menggerakkan tubuhnya di pusat gravitasi sendiri(titik tengah tubuh bagian atas) secara lateral ke kanan dan kiri ke titik di mana atlet akan mengalami kehilangan keseimbangan, dengan demikian fungsi otot lateral trunk dan abdomen oblik dapat dievaluasi serta otot lumbar/otot punggung bawah

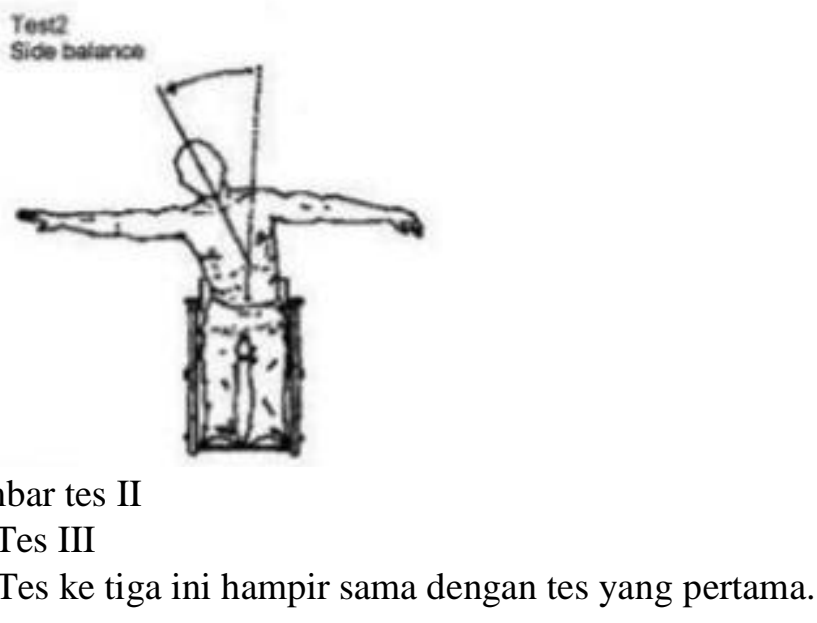

Tes ekstensi tubuh, tetapi lebih khusus di otot lumbar/pungguh bawah otot. Tes ini dilakukan dengan tangan di belakang leher, sehingga tidak termasuk kedua komponen inersia dari gerakan tungkai atas dan bantuan otot punggung atas tubuh.

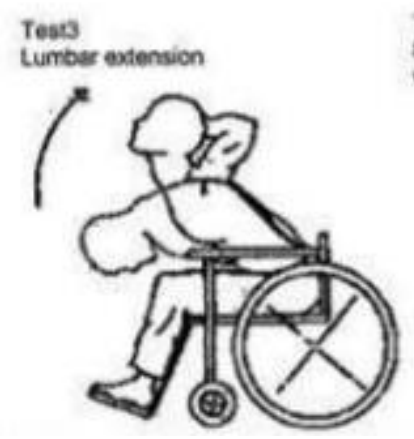




\section{Klasifikasi Disabilitas Atlet Anggar Kursi Roda (Wheelchair Fencing) Untuk Kejuaraan Internasional}

Joko Nugroho

Gambar tes III

4) Tes IV

Tes ke empat ini hampir sama dengan tes yang ke dua, tes yang ke empat ini lebih sulit karena harus dieksekusi dengan memegang senjata, yang bobotnya secara signifikan mengurangi kemungkinan bagian lateral tubuh tanpa kehilangan keseimbangan.

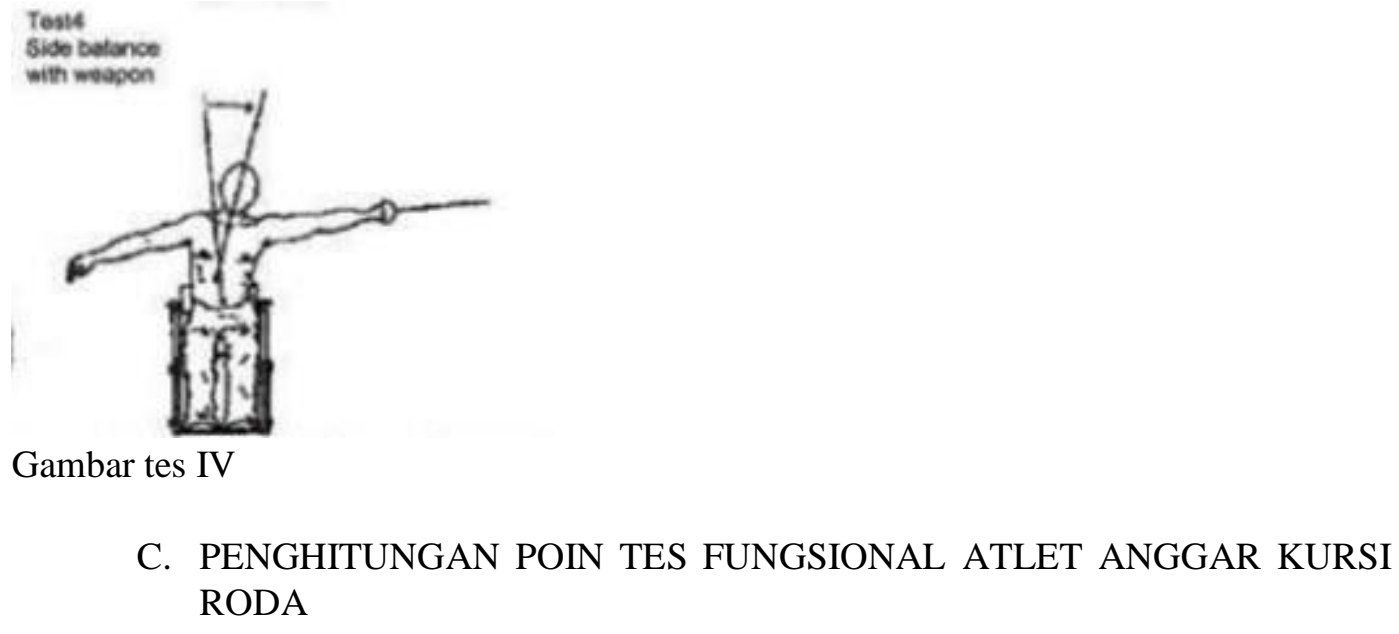

Dalam penghitungan poin untuk menentukan klasifikasi atlet ini harus didasarkan pada disabilitasnya dan hasil dari poin-poin yang didapatkan oleh atlet yang bersangkutan, adapun penentuan poin itu sebagai berikut;

a. Untuk seorang atlet yang terkena cacat tulang belakang (paraplegia atau polio) kekuatan otot dievaluasi dengan skor poin dari $0-5$. Tes yang dilaksanakan dengan penambahan tindakan adduksi bahu, resistensi ibu jari, rotasi pinggul dan lutut, supinasi kaki yang disabel dan tidak memiliki jari.

b. Untuk atlet yang terkena spastisitas, distonia atau athetosis, poin diberikan untuk setiap tindakan terkontrol sebagai berikut:

1 poin : titik gerakan tidak fungsional, koordinasi motor minimal atau tidak ada.

2 poin : gerakan terjadi sangat lambat dan dengan susah payah. Jika

dilakukan dengan pengulangan yang cepat, tidak akan melebihi $25 \%$ dari kisaran pergerakan normal.

3 poin : seperti di atas, hingga 50\% dari rentang pergerakan penuh.

4 poin : sedikit koordinasi gerakan dan / atau tidak lebih dari $75 \%$ dari rentang gerakan normal.

5 poin : koordinasi motorik normal.

c. Dalam kasus cedera yang berasal dari ortopedi, dan karena itu seseorang dihadapkan dengan masalah ankylosis/gangguan pada sendi bahkan tulang melekat satu dengan lainnya atau bahkan patologi laten dalam pengurangan rentang pergerakan, skor poin dari 0 hingga 5 dinyatakan sebagai berikut:

0 poin : tidak ada rentang gerakan sama sekali

1 poin : Rentang gerakan minimal

2 poin : $1 / 4$ dari rentang pergerakan normal

3 poin : $1 / 2$ dari rentang pergerakan normal

4 poin : $3 / 4$ dari rentang pergerakan normal

5 poin : rentang pergerakan normal 


\section{Klasifikasi Disabilitas Atlet Anggar Kursi Roda (Wheelchair Fencing) Untuk Kejuaraan Internasional}

Joko Nugroho

\section{HASIL KLASIFIKASI ATLET ANGGAR KURSI RODA}

Setelah evaluasi analisis berdasarkan disabilitasnya dan tes fungsional, klasifikasi diberikan sesuai dengan kriteria berikut:

a. Atlit Kelas 1A tanpa keseimbangan duduk yang memiliki lengan untuk bergerak cacat. Tidak ada ekstensi siku yang efisien melawan gravitasi dan tidak ada fungsi sisa tangan yang membuatnya perlu untuk memperbaiki senjata dengan perban. Kelas ini sebanding dengan tetraplegik dengan tingkat lesi tulang belakang C5 / C6.

b. Atlit Kelas 1B tanpa keseimbangan duduk dan lengan memegang senjata yang terkena dampak. Ekstensi siku fungsional tetapi tidak ada fleksi jari. Senjatanya harus dibantu dengan tali/perban. Sebanding dengan menyelesaikan level tetraplegics $\mathrm{C} 7$ / C8 atau lesi tidak lengkap yang lebih tinggi.

c. Atlet Kelas 2 dengan keseimbangan duduk yang adil dan lengan memegang anggar/memegang senjata normal, tipe lumpuh D1 - D9 (Tes fungsional 1 dan 2 tidak berjumlah total lebih dari 4 poin) atau tetraplegics tidak lengkap dengan lengan pagar yang terkena dampak minimal dan keseimbangan duduk yang baik.

d. Atlet Kelas 3 dengan keseimbangan Duduk yang baik, tanpa dukungan kaki dan lengan pagar yang normal, lumpuh dari D10 ke L2 (Tes fungsional 1 dan 2 positif dengan skor poin dari 5 hingga 9). Subjek dengan double di atas amputasi lutut dengan tunggul pendek, atau lesi tidak lengkap di atas D10 atau cacat yang sebanding dapat dimasukkan dalam kelas ini, asalkan kaki dapat membantu menjaga keseimbangan duduk.

e. Atlet Kelas 4 dengan keseimbangan duduk yang baik dengan dukungan tungkai bawah dan lengan anggar normal, dengan lesi di bawah L4 atau cacat yang sebanding (tes 3 dan 4 positif dengan setidaknya 5 poin). Kecacatan pada ekstremitas bawah sebanding dengan amputasi di bawah lutut.

\section{E. KATAGORI ATLET ANGGAR KURSI RODA}

Komite klasifikasi atlet akan memberikan katagori kartu klasifikasi yang sesuai dengan poin yang sudah ditentukan,sering kali terjadi beberapa kasus yang mengharuskan komite klasifikasi mengadakan pengamatan secara visual kepada atlet saat atlet mengadakan pemanasan sebelum pertandingan dilaksanakan, kasus ini muncul dikarenakan tim klasifikasi belum yakin saat pengukuran fungsional dilakukan oleh atlet yang bersangkutan. Tim klasifikasi masih meragukan atlet saat melakukan tes fungsional tidak dengan sepenuh hati atau memang dengan sengaja membuat gerakan gerakan yang terbatas dengan maksud agar mendapatkan klasifikasi yang diinginkan. Biasanya atlet menghendaki masuk di katagori klasifikasi B agar persaingan antar atlet sedikit dan peluang mendapatkan juara menjadi besar.

Ada tiga kategori klasifikasi untuk setiap pertandingan individu. A., B. dan C. 


\section{Klasifikasi Disabilitas Atlet Anggar Kursi Roda (Wheelchair Fencing) Untuk Kejuaraan Internasional}

Joko Nugroho

1: A: Atlet yang masuk di kelas 3 dan 4 .

2: B: Atlet yang masuk di kelas 2 .

3: C: Atlet yang masuk di kelas 1A-1B

\section{PENUTUP}

Olahraga penyandang disabilitas khususnya anggar kursi roda masih sangat sedikit peminat dan pelakunya, hal ini dikarenakan beberapa hal yang salah satunya keterbatasan sarana dan prasarana di setiap daerah. Pemasalan olahraga anggar kursi roda ini perlu dilakukan, salah satunya memberi pemahaman kepada masyarakat khususnya bagi kaum disabilitas bahwa cabang anggar kursi roda ini mudah dilakukan dan memiliki peluang yang besar dalam meraih prestasi puncak, masyarakat kususnya kaum penyandang disabilitas juga harus memahami akan nomor-nomor yang dipertandingkan dan katagori klasifikasi atlet anggar kursi roda. Dengan pemahaman dan pengetahuan akan olahraga anggar kursi roda ini diharapkan masyarakat khususnya penyandang disabilitas yang sesuai dengan katagori klasifikasi olahraga ini dapat mempersiapkan diri sejak awal untuk menekuni dan berlatih anggar kursi roda, dan harapan memperoleh prestasi melalui event internasional mudah tercapai. Dengan peraihan prestasi yang baik di multi event internasional maka secara otomatis tingkat ekonomi atlet akan membaik dikarenakan adanya bonus pemerintah yang sekarang sudah sangat layak dan bisa dijadikan tolak ukur kehidupan seorang atlet.

Daftar Pustaka:

IWAS, International Wheelchair and Amputee Sport Federation, Wheelchair Fencing Rules for Competition

Introduction to The Three Weapons, tie.org/new-to-fencing/weapons(21/08/19)

Technical handbook Asian Para Games 2018 Wheelchair Fencing, Jakarta Inapgoc 2018 